www.jmscr.igmpublication.org

Impact Factor (SJIF): 6.379

Index Copernicus Value: 79.54

ISSN (e)-2347-176x ISSN (p) 2455-0450

crossrefDOI: https://dx.doi.org/10.18535/jmscr/v6i10.213

\title{
Sexual function status after Transurethral resection of prostate (TURP)
}

\author{
Authors \\ Hossain $F^{1}$, Rahman $S^{2}$, Rahman $H^{3}$, Alam AKMK ${ }^{4}$, Faruque MDS ${ }^{5}$, Rahman $Z^{6}$ \\ ${ }^{1}$ Assistant Professor, Department of Urology, BSMMU, Dhaka \\ ${ }^{2}$ Consultant, Radiology \& Imaging, Module General Hospital, Dhaka \\ ${ }^{3,4}$ Professor, Department of Urology, BSMMU, Dhaka \\ ${ }^{5}$ Associate Professor, Department of Urology, BSMMU, Dhaka \\ ${ }^{6}$ Associate Professor, Department of Oncology, BSMMU
}

\begin{abstract}
Background: There is a link between Low Urinary Tract Symptoms (LUTS) and deterioration of sexual function in men $>50$ years of age and for which transurethral resection of the prostate (TURP) is considered the gold standard treatment despite the new minimally invasive surgical options.

Objectives: To evaluate the change in sexual function status after TURP in elderly Bangladeshi males.

Methods: One hundred patients presenting with BPH and treated with transurethral resection of prostate (TURP) in the Department of Urology, BSMMU, Dhaka from January2016 to December 2016 over a period of one year were evaluated for postoperative sexual function.

Results: The mean age of the patients was $61.21 \pm 7.21$ years while the mean duration of lower urinary tract symptoms was $24.3 \pm 6.40$ months. Of the 91 patients with a living wife/partner, $44(48.4 \%)$ had active sex lives preoperatively, 38(41.8T) of them had good erections whereas $6(6.6 \%)$ had weak erections though they were able to have satisfactory penetration. All 44 (48.4\%) had normal ejaculation prior to TURP. In the postoperative follow up, 10 (22.7\%) of these 44 patients reported an improvement in their sex life in terms of increased libido and improved erections. Twenty-one (47.7\%) had no change in their status after TURP, but were satisfied with their sex life. The remaining $13(29.5 \%)$ had deterioration in their status in terms of decreased libido and poor erections.

Conclusions: About 48.4\% of patients with a living spouse/partner are sexually active at the time of undergoing TURP. TURF leads to a deterioration of sexual function in up to $29.5 \%$ of these patients. This includes both loss of libido and erections.

Keywords: TURP, Erection, Libido.
\end{abstract}

\section{Introduction}

Lower urinary tract symptoms (LUTS) and sexual dysfunction are highly prevalent in aging men $^{1}$; recent evidences from both community and clinical trials, in fact, have suggested a link between these two conditions. ${ }^{2,3}$ Transurethral resection of the prostate (TURP), the standard surgical therapy for the treatment of bladder outlet obstruction (BOO) caused by benign prostatic hyperplasia (BPH), is also reported to cause sexual dysfunction as well. It is known that TURP may cause retrograde ejaculation, but its effect on erectile function is still controversial. ${ }^{4,5}$ Previous studies have shown that the incidence of erectile 
dysfunction (ED) after TURP is between $4 \%$ and 40\%. ${ }^{4,6}$ According to a systematic review, approximately $75 \%$ of sexually active and potent patients experienced retrograde ejaculation and over $13 \%$ reported ED after TURP, ${ }^{7}$ although in some studies erectile function either improved after TURP or did not change. ${ }^{8,9}$

There is no data available on sexual function of the aging Bangladeshi male. There is also no Bangladeshi data on the effects of BPH on sexual function and its improvement or deterioration after TURP. This study aims to answer these questions.

\section{Methods}

One hundred patients aged more than 50 years planned for TURP for standard indications were evaluated for sexual function status before and after surgery during the period from January 2016 to December 2016. A 10-point questionnaire was used to subjectively assess sexual function before surgery and at 3 and 6 months after treatment. Some patients were evaluated at 12 months also. Sterile $1.5 \%$ glycine solution was used as the irrigating fluid. A 22 French 3 way Foley catheter was inserted at the end of the procedure and bladder irrigation continued for 12 to 24 hours. The catheter was removed the following morning or in some cases on the second postoperative morning. All patients voided satisfactorily after the catheter removal. There was no incidence of TUR syndrome. Follow-up visits were advised at 6 months.

\section{Results}

Out of the 100 patients, $9(9.0 \%)$ had no sex partners or wives. Of the remaining 91, 44 (48.4\%) were sexually active before TURP. This included $9(9.9 \%)$ patients who were catheterized later, but were sexually active before developing acute retention (Table 1). Of the 91patients, 44 were sexually active and 36 of them had good erections. Ten $(22.7 \%)$ patients reported an improvement in their sex lives in terms of increased libido and erections. Twenty-one (47.7\%) patients had no change in their sexual performance status but were satisfied with their sex life. The remaining 13patients had poor libido or erections though they had considerable improvement in their urinary symptoms (Table 2).

Table 1: Patients Characteristics

\begin{tabular}{lc}
\hline Patients characteristics & Mean \pm SD/n(\%) \\
\hline Age (years) & $61.21 \pm 7.21(50-78)$ \\
Duration of symptoms (months) & $24.30 \pm 6.40(12-36)$ \\
Having wives/sex partners & $91(91.0)$ \\
Sexually active & $44(48.4)$ \\
Good erections & $38(41.8)$ \\
Weak erections & $6(6.6)$ \\
Sexually active but catheterized & $9(9.9)$ \\
\hline
\end{tabular}

Table 2: Post TURP results

\begin{tabular}{lccccc}
\hline Age (years) & Patients & Pre op active & \multicolumn{3}{c}{ Post operative status } \\
\cline { 4 - 6 } & $\mathrm{n}(\%)$ & $\mathrm{n}$ & Improved & No change & $\begin{array}{c}\text { Deteriorated } \\
\mathrm{n}(\%)\end{array}$ \\
\hline $50-59$ & & & $5(21.7 \%)$ & $13(56.5 \%)$ & $5(21.7 \%)$ \\
$60-69$ & $42(42.0 \%)$ & 18 & $4(22.2)$ & $7(38.9)$ & $7(38.9)$ \\
$70-79$ & $49(49.0 \%)$ & 3 & $1(33.3)$ & $1(33.3)$ & $1(33.3)$ \\
Total & $9(9.0 \%)$ & 44 & $10(22.7)$ & $21(47.7)$ & $13(29.5)$ \\
\hline
\end{tabular}

\section{Discussion}

Libido and erection decline in men with age. ${ }^{10-14}$ The Cologne male survey, ${ }^{10}$ found that the average prevalence of erectile dysfunction was $19.2 \%$ (6\% of $38-47$ year olds were sexually inactive compared to $71.35 \%$ of $60-70$ years old). 
The Krimpen study surveyed 1688 men found 3\% incidence of erectile dysfunction in those 50-54 years old and $26 \%$ in those $70-80$ years old. ${ }^{12}$ This study found $48.4 \%$ of patients who had wife/partner were sexually active before TURP. Hernandez et al. ${ }^{15}$ found59\% of patients were sexually active prior to surgery. Mishriki et al. ${ }^{16}$, in a study of 120 sexually active men before TURP, found all of them sexually active at 6 months following TURP. In this study, it was noted a decline in sexual function in $29.5 \%$ of the patients after surgery. Thus number is comparable to the $26.0 \%$ noted by Arai ${ }^{17}$ But Hernandez et al. ${ }^{15}$ found only $5.65 \%$ incidence of deterioration in sexual function. The overall incidence of deterioration in sexual performance after prostatectomy in other studies ranges from $7 \%$ to $40 \%{ }^{18-21}$ The deterioration in function maybe a result of damage to neurovascular bundles, altered body image or complications such as incontinence or stricture.

Another issue relates to the recovery of sexual function after TURP, Hernandez ${ }^{15}$ reported an improvement in $66 \%$ of their patients, none of our patients who were inactive pre-operatively showed any improvement. However, $22.7 \%$ of those previously active had an improvement.

\section{Conclusions}

Up to $48.4 \%$ of males undergoing TURP were sexually active. One third of them experienced a decline in sexual function after surgery. Any recovery of sexual function after surgery in inactive patients was absent.

\section{References}

1. Rosen R, Altwein J, Boyle P, et al. Lower urinary tract symptoms and male sexual dysfunction: the multinational survey of the aging male (MSAM-7). Eur Urol 2003, 44: 637-49.

2. Morgia G, Cimino S, Favilla V, et al. Effects of Serenoa Repens, Selenium and Lycopene (Profluss (R)) on chronic inflammation associated with benign prostatic hyperplasia: results of "FLOG" (Flogosis and Profluss in Prostatic and Genital Disease), a multicentre Italian study. Int Braz J Urol 2013, 39: 214-21.

3. van Dijk M, Skrekas T, de la Rosette JJ. The association between lower urinary tract symptoms and sexual dysfunction: fact or fiction? Cur rOpinUrol 2005, 15: 39-44.

4. Brookes ST, Donovan JL, Peters TJ, et al. Sexual dysfunction in men after treatment for lower urinary tract symptoms: evidence from randomised controlled trial. BMJ 2002, 324: 1059-61.

5. Rassweiler J, Teber D, Kuntz R, Hofmann R. Complications of transurethral resection of the prostate (TURP) - incidence, management, and prevention. Eur Urol 2006, 50: 969-79 (Discussion 80).

6. Kassabian VS. Sexual function in patients treated for benign prostatic hyperplasia. Lancet 2003, 361: 60-2.

7. Vale J. Benign prostatic hyperplasia and erectile dysfunction - is there a link? Curr Med Res Opin 2000, 16(Suppl 1): s63-7.

8. Jaidane M, Arfa NB, Hmida $\mathrm{W}$, et al. Effect of transurethral resection of the prostate on erectile function: a prospective comparative study. Int J Impot Res 2010, 22: $146-51$.

9. Choi SB, Zhao C, Park JK. The effect of transurethral resection of the prostate on erectile function in patients with benign prostatic hyperplasia. Korean J Urol 2010, 51: 557-60.

10. Braun M, Wassmer G, Klotz T, Reifenrath B, Mathers M. Engelmann U. Epidemiology of erectile dysfunction: results of the 'Cologne finale survey'. Int $\mathbf{J}$ Impot Res 2000; 12(6): 305-11.

11. Avis NE. Sexual function and aging in men and women: community and population-based studies. J GendSpecif Med 2000; 3(2): 37-41. 
12. Blanker MH, Bosch JL, Groeneveld FP, Bohnen AM, Prins A, Thomas S, Hop WC. Erectile and ejaculatory dysfunction in a community-based sample of men 50 to 78 years old: prevalence, concern and relation to sexual activity. Urology 2001; 57(4): 763-8.

13. Weidner W, Altwein J. Hauck E, Beutel M, Brahler E: Sexuality in the elderly: Urol Int 2001; 66: 181-4.

14. Marumo K, Nakashima J, Murai M. Agerelated prevalence of erectile dysfunction in Japan: assessment by the International Index of Erectile Function. Int $\mathbf{J}$ Urol 2001; 8(2): 53-9.

15. Hernandez Millan I. Salinas Sanchez A, Romero JL, Segura Martin M, Virseda Rodriguez J. Sexual activity and surgery of benign prostatic hyperplasia. Arch EspUrol 2001; 54(1): 53-60.

16. Mishriki FS, Cohen NP, Mawas A, Gibbons B. TURP can improve your sex life. Abstract no. 1501, AUA 2001.

17. Arai Y, Aoki Y. Okubo K, Maeda H, Terada N, Matsuta $\mathrm{Y}$ et al. Impact of interventional therapy for benign prostatic hyperplasia on quality of life and sexual function. A prospective study. J Urol 2000; 164: 1206-11.

18. Holtgrewe HL, Valk WL. Late results of transurethral prostatectomy. J Urol 1964; 92: 51-5.

19. Finkle AL, Prian DV. Sexual potency in elderly men before and after prostatectomy. JAMA 1966; 196: 139-43.

20. Zlotta AR, Schulman C. BPH and sexuality. Eur Urol 1999; 36: 107-12.

21. Hargreave TB, Stephenson TP. Potency and prostatectomy. Br J Urol 1977; 49(7): 683-8. 